\title{
FUNÇÃO CóCLEO-VESTIBULAR APóS HEMISFERECTOMIAS CEREBRAIS. APRESENTAÇÃO DE DOIS CASOS
}

\author{
SÉrgio Paula Santos* \\ ANTONIO CORRÊA**
}

As observações sôbre o comportamento do nervo estatoacústico nas lesões corticais são pouco numerosas devido, entre outras razões, à dificuldade de interpretação das alteraçōes cócleo-vestibulares nas afecções cerebrais. Pretendemos neste trabalho contribuir para o estudo da semiologia do VIII $^{\circ}$ par apresentando os dados obtidos no exame de dois pacientes submetidos à hemisferectomia total.

\section{Anátomo-fisio-patologia do sistema coclear}

O nervo coclear, condutor dos impulsos originados no órgão de Corti, é constituido por fibras cujas células estão no gânglio espiral e cujos prolongamentos centrais (10 neurônio) vão ter aos núcleos cocleares no bulbo; a partir dos dois núcleos bulbares, dorsal e ventral, segue-se o $2^{\circ}$ neurônio, cujas fibras dividem-se em homolaterais $(1 / 3)$ e heterolateriais $(2 / 3)$, sendo que estas cruzam o assoalho do $4^{\circ}$ ventrículo formando o corpo trapezóide. Em cada metade do tronco cerebral existem, portanto, fibras cocleares homo e heterolaterais, que terminam no corpo geniculado medial e no colicúlo inferior, centros dos reflexos cocleares. No mesencéfalo existem fibras de associação entre as duas vias acústicas, direita e esquerda, como também tem origem o terceiro neurônio, segundo alguns autores. Segundo outros êste $3^{\circ}$ neurônio inicia-se no tálamo e dai atinge o centro acústico cerebral, localizado no girus de Heschl, na face dorsal da primeira circunvolução temporal. A representação cortical da audição tem sido estudada, principalmente, mediante pesquisas de eletrofisiologia em animais e, mais raramente, por observações anátomo-clinicas. Os conceitos estabelecidos estão sujeitos a revisão e permitem apenas uma idéia aproximativa da realidade dos fatos. No girus de Heschl está localizada a área de percepção sonora, provàvelmente, com distribuição tonal, de acôrdo com a frequência. Em áreas próximas do lobo temporal se localizariam zonas para reconhecimento dos sons (palavra falada, música, expressão simbólica). Os centros psíquicos da audição estariam localizados no hemisfério esquerdo para os dextros e no hemisfério direito para os canhotos. Os centros acústicos corticais, de um e outro lado, são ligados por fibras inter-hemisféricas; assim o lobo temporal de um lado tem a representação das cócleas direita e esquerda, possibilitando adaptação dos distúrbios auditivos corticais após hemisferectomias.

Trabalho do Serviço de Otorrinolaringologia da Fac. de Med. da Univ. de São Paulo (Prof. Raphael da Nova), apresentado ao Departamento de Otorrinolaringologia da Associação Paulista de Medicina em 17-9-1956 e na 5* Reunião da Federação das Soc. Brasil. de Otorrinolaringologia e Broncoesofagologia, em São Paulo, setembro, 1956: * Médico adido; ** Assistente e Chefe de Clinica. 
A ressecção de um lobo temporal produz um déficit ligeiro, predominantemente controlateral, nos testes limiares da audição e distúrbios supra-limiares, tais como aumento na diferenciação da intensidade sonora e diminuição da discriminação da palavra falada. No que se refere à função coclear nas afecções do lobo temporal, encontramos, na literatura, referências a 107 casos de ressecções (99 hemisferectomias e 8 lobectomias); em apenas 10 dêsses casos foi feito exame audiométrico, cujos resultados citaremos a seguir. A hipoacusia é bilateral, quase sempre simétrica e de pequena inten-

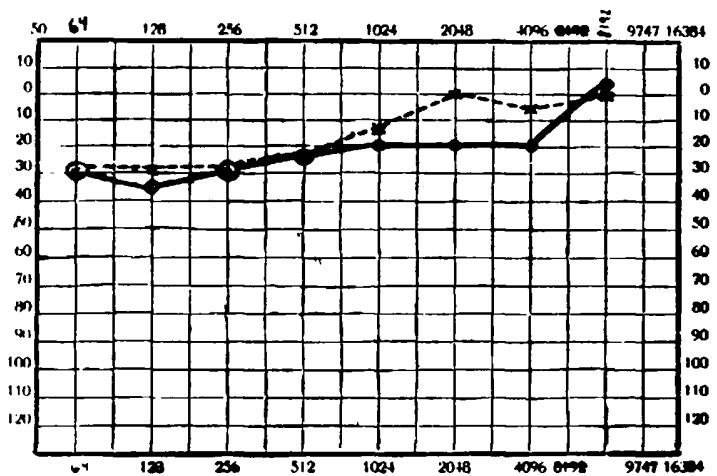

Fig. 1 - Audiometria em caso de hemisferectomia à direita (observação de Bunch, cit.. ${ }^{2}$ ).



Fig. 2 - Audiometria em caso de lobectomia temporal à esquerda (observação de Barré, Vincent e Helle ${ }^{3}$ ).

sidade. A queda de audição pode predominar em um dos ouvidos, geralmente no lado oposto ao que foi operado. O campo auditivo pode restringir-se seja no limite inferior, como no caso de Bunch (cit por Saltzmann ${ }^{2}$ ) de hemisferectomia direita (fig. 1), seja no limite superior como no caso de Barré, Vincent e Helle ${ }^{3}$, de lobectomia esquerda (fig. 2). A surdês total ocorreria ape- 
nas depois de lesões bilaterais dos giros de Heschl, o que é expecional, como no caso de Le Gros e Russel (cit. por Spiegel e Sommer ${ }^{4}$ ). Não se pode atribuir a queda de audição após ressecção do lobo temporal ao traumatismo cirúrgico, pois que a remoção de outras partes da cortex cerebral não determina hipoacusia. A experiência mostra que algum tempo depois da lobectomia temporal unilateral há recuperação parcial ou total da hipoacusia pósoperatória imediata. Klüver e Bucy (cit. por Terzian e col.5) descreveram, em 1947, um complexo quadro neurológico obtido em macacos rhesus, decorrente da ablação dos dois lobos temporais, incluindo uncus e o hipocampo; dêsse quadro neurológico fazia parte a "agnosia visual" ou "cegueira psiquica". Em 1955, Terzian e Dalle Oro ${ }^{5}$ publicaram um caso notável de "síndrome de Klüver e Bucy" num paciente em que foram removidos os dois lobos temporais, incluindo o uncus e o hipocampo; nesse paciente, entretanto, não se instalcu a "agnosia visual" e a audição pós-operatória, embora não fosse medida instrumentalmente, era sociável.

Nas lesōes do órgão de Corti tem sido verificada uma recuperação do volume sonoro à medida que se investiga a capacidade auditiva em níveis acima do limiar de audibilidade, constituindo o fenômeno do recrutamento, pesquizado por meio de diferentes testes supralimiares. Nas lesões centrais das vias auditivas pode ser encontrada a redução proporcional do volume sonoro em niveis supralimiares de audição, fenômeno denominado inversão de recrutamento, clàssicamente atribuido às lesões retro-labirínticas e que nem sempre aparece nas hemisferectomias cerebrais. Greiner, Kantzer e Rohmer ${ }^{6}$ apresentam detalhado estudo de 6 pacientes submetidos à lobectomia temporal, nos quais estudaram a audiometria tonal e o limiar diferencial de intensidade, sugerindo o emprêgo de um novo teste, que consiste em repetir o audiograma usando-se um som mascarador grave na própria orelha testada; concluiram que nos pacientes lobectomizados o limiar diferencial é maior do que nos indivíduos normais e que a influência do mascaramento é geralmente maior, mais irregular e desproporcional em relação ao pequeno déficit mostrado na audiometria tonal.

\section{Anátomo-fisio-patologia do sistema vestibular}

O sistema vestibular, no estado normal, responde às estimulacões como um todo, organizado como está em duas metades, anatomicamente distintas, mas de funçōes complementares. O nervo vestibular, originado no labirinto posterior, termina nos núcleos vestibulares do bulbo, os quais entram em conexão com o cerebelo, com os núcleos motores do tronco cerebral e da medula, ajustando as reações dos músculos do corpo aos movimentos que êste executa ou às posiçōes que toma no espaço (função de equilibrio). Nos hemisférios cerebrais, taivez nas porções posteriores dos lobos temporais, se localizariam centros vestibulares corticais que teriam a capacicidade de perceber a sensação vestibular e seriam capazes de controlar os reflexos motores de origem vestibular.

Apesar da alta incidência da vertígem nas lesões do lobo temporal, a sintomatologia vestibular não serviria de guia quanto à localização da lesão cerebral. A presença do nistagmo espontâneo ou de posição, assim como 
as alteraçōes do nistagmo provocado (provas vestibulares) estariam relacionadas com distúrbios indiretos dos núcleos $\mathrm{e}$ vias vestibulares localizados no tronco cerebral. Para alguns autores (Carmichael e col. ${ }^{1}$ ) as lesōes do lobo temporal influem na função vestibular; desde que haja destruição ou ressecção da áréa vestibular cortical, o nistagmo provocado calórico terá direção predominante para o lado da lesão. Assim, a ação do lobo temporal seria a de modificar o nistagmo vestibular, através de fibras corticífugas que vão ter aos núcleos vestibulares bulbares.

Nos nossos casos verificamos a função vestibular só pela técnica de Veits, medindo a frequência e o tempo de reação nistágmica provocada por $20 \mathrm{ml}$ de água a $20^{\circ} \mathrm{C}$.

\section{OBSERVACOES}

Caso 1 - A. L. G., 18 anos, sexo masculino, branco, examinado em 18-10-1954 (R. G. 388.455). Aos 4 anos de idade, após moléstia febril com duração de um mês, instalou-se hemiplegia esquerda com manifestaçōes convulsivas do tipo generalizado. O paciente frequentou escola até o terceiro ano primário quando interrompeu o estudo por irritabilidade fácil e pouca sociabilidade. Os exames clínico, neurológico e psiquico conduziram ao diagnóstico de hemiplegia infantil com epilepsia e distúrbios da conduta. O paciente foi operado de hemisferectomia direita em 6-12-1954 no Servico de Neurocirurgia (Dr. R. Tenuto), sendo excisado todo hemisfério cerebral direito, inclusive parte do núcleo caudado e todo o núcleo amigdalóide.

O exame audiométrico foi realizado 16 meses após a intervenção cirúrgica. O paciente estava consciente, lúcido, com capacidade de concentração e cooperava com o examinador, o que permitiu a execução da audiometria tonal e vocal, bem como dos testes supra-limiares. Para a audiometria vocal, utilizamos os discos com listas de dissilabos e de monossílados da lingua portuguêsa, de Geraldo de Sá ${ }^{7}$. As listas de dissilabos serviram para teste limiar (50\% de palavras ouvidas são repetidas certas) e para determinação do indice de adequabilidade social aplicando o gráfico de Walsh, Silverman e Davis, o que dará um valor aproximado para a lingua portugusêa. As listas de monossilabos fonèticamente balanceados (F. B.) foram utilizados para medir o teste de discriminação, de valor diagnóstico topográfico da lesão acústica.

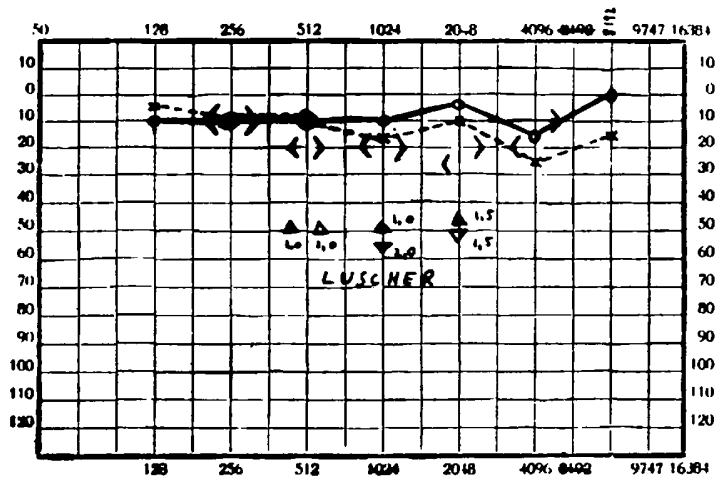

Fig. 3 - Cáso 1 (A. L. C.) Audiometria 16 meses após hemisferectomia direita. 
Os dados obtidos foram os seguintes: Otoscopia: membranas normais e móveis com o espéculo de Ziegler. Diapasôes: o paciente ouve tôda a série, de C a $C_{5}$, igualmente em ambos ouvidos; Weber indiferente (colocado o diapasão nos dentes incisivos e no queixo); Rinne positivo em ambos ouvidos; Schwabach normal em ambos ouvidos. Audiometria tonal limiar: ligeira hipoacusia de percepçăo bilateral, predominante em 4.096 e do ouvido esquerdo (Fig. 3); teste supra-limiar de Luscher-Zwislocki, foi pesquizado em 500, 1000 e 2000 não mostrando recrutamento nem inversão do recrutamento; os valores obtjdos foram de 1,0 a $2,0 \mathrm{db}$. Audiometria vocal: 1) Teste limiar em $\mathrm{OD}=10 \mathrm{db} ; 2)$ F. B. teste, em $\mathrm{OD}=$ $68 \%$, em $\mathrm{OE}=72 \%$; 3) Indice de adequabilidade social, em $\mathrm{OD}=65$, em $\mathrm{OE}=62$. Prova vestibular calórica fria (técnica de Veits) - Normorreflexia à direita e discreta hiperreflexia à esquerda.

Caso 2 - A. G., 26 anos, sexo masculino, branco (R. G. 163.254). Em 27-7-1950, o paciente foi internado no Pronto Socorro em torpor profundo, desorientado no tempo e no espaço; a punção lombar forneceu liquor francamente hemorrágico; após uma série de exames foi diagnosticada malformação vascular no lobo frontal e parietal esquerdos (artéria cerebral média). O paciente teve alta em maio de 1950. Em julho de 1955, foi novamente internado, outra vez em torpor profundo, com hemiplegia total à direita e afasia motora. Os exames mostraram ter havido nova hemorragia cerebro-meningéia. Tendo sido excluida a possibilidade de excisar a malformação vascular dada sua extensão em superfície e em profundidade foi praticada a hemisferectomia esquerda, realizada em 5-12-1955 (Dr. $R$. Tenuto), sendo removido todo o hemisfério cerebral esquerdo, além do corpo caloso $e$ parte dos núcleos da base. No pós-operatório ocorreu otite média aguda purulenta, curada em 7 dias, com cicatrização completa da membrana timpânica. Em decorrência da intervenção manifestou-se além da afasia motora pré-existente, afasia sensorial que regrediu em aproximadamente um mês, enquanto os distúrbios motores da palavra permaneceram. O paciente foi submetido à reeducação fonética, com poucos resultados; fala apenas monossilabos (bom, bem etc.) entendendo, entretanto, pelo menos aparentemente, o que se lhe diz.

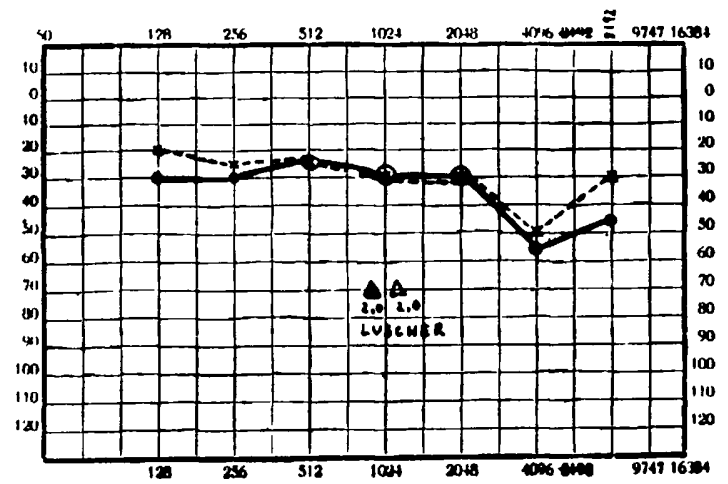

Fig. 4 - Caso 2 (A. G.). Audiometria 4 meses após hemisferectomia esquerda.

Exame otológico (realizado 4 meses após a hemisferectomia) -- otoscopia: membranas de côr e aspecto normais, móveis com o espéculo de Ziegler. Diapasões: paciente ouve tôda a série, de $\mathrm{C}$ a $\mathrm{C}_{5}$, em ambos ouvidos; Weber lateralizado para a esquerda; Rinne positivo em A. O.; Schwabach normal em A. O. Audiograma tonal limiar: hipoacusia bilateral, global, predominante nos agudos (4.096) (fig. 4). Teste supra-limiar (Luscher-Zwislocki): não há recrutamento, nem inversão do 
mesmo; foi pesquizado na frequência de 1.024 e deu como resultado $2,0 \mathrm{db}$. Audiometria vocal: não pôde ser realizada em virtude da afasia motora apresentada pelo paciente. Prova vestıbular calórica fria (técnica de Veits): normorreflexia bilateral.

\section{COMENTARIOS}

O comportamento da função auditiva nos pacientes por nós observados coincide, de modo geral, com os relatados na literatura consultada. Assim, em ambos os casos as quedas da audição foram bilaterais e quase idênticas, discretamente mais acentuadas no ouvido contralateral, fato êsse em que quase todos autores concordam (Portmann e col. ${ }^{8}$, Saltzmann ${ }^{2}$, Tunturi ${ }^{9}$ ), não ultrapassando a $30 \mathrm{db}$, com excessão da frequência de 4.096. Há restrição do campo auditivo, ainda que mínima, no limite superior, o que concorda com a observação de Barré, Vincent e $\mathrm{Helle}^{3}$. No caso 2, a queda média da audição está ao redor de $30 \mathrm{db}$ (com excessão da frequência de 4.096 v.d.), sendo ligeiramente mais acentuada no ouvido contralateral. O campo auditivo está restringido bilateralmente, sendo maior a perda no limite inferior como aconteceu na observação de Bunch ${ }^{2}$. Na primeira observação devemos assinalar que os dados logoaudiométricos não coincidem com os da audiometria tonal, que são sensivelmente superiores. Assim, o índice de adequabilidade social (I. A. S.) em individuos considerados de audição normal está ao redor de 94 , e no nosso doente obtivemos as grandezas de 65 (ouvido direito) e 62 (ouvido esquerdo).

A desproporcionalidade entre os achados da audiometria tonal e vocal parece ser uma das características das lesões corticais, sendo as alterações da integibilidade mais intensas do que faria supor a hipoacusia tonal. De modo geral, os resultados que obtivemos são idênticos aos de outros autores, inclusive com os de Greiner e cols. ${ }^{6}$, cujos testes põem em jôgo funções mais complexas que a simples percepção sonora. A pesquisa de alterações subjetivas da audição e a descoberta de testes clínicos para estudo destas alterações, facilitarão, no futuro, a localização de afecções nos lobos temporais.

No que se refere à função vestibular, confirma-se a opinião geralmente aceita, de que o nistagmo provocado é independente de prováveis centros localizados nos lobos temporais. A normorreflexia vestibular obtida na prova calórica fria, na verdade, é um dado incompleto por não ter sido feita a prova com água quente. Lembramos, no entanto, que não há elementos para suspeitar a existência de uma predominância de direção nistágmica provocada, de acôrdo com Cawthorne e cols. ${ }^{10}$.

\section{RESUMO}

O exame cócleo-vestibular de dois pacientes hemisferectomizados mostrou: hipoacusia bilateral não ultrapassando $30 \mathrm{db}$, sendo maior no ouvido contralateral; não houve recrutamento de volume; desproporção entre audiometria vocal e tonal; a função vestibular não se mostrou prejudicada pela prova calórica fria. 


\section{SUMMARY}

Cochleo-vestibular functions after hemispherectomy. Report of two cases.

Report of cochleo-vestibular examinations of two patients in which hemispherectomy was performed, respectivelly 16 and 4 months before. Both patients presented: bilateral hipoacusia (maximal perception of $30 \mathrm{db}$ ), the greater hearing loss being contralateral to the side of excision; absence of recruitment phenomenon; desproportion between tonal and vocal audiometry. Vestibular reactions to caloric test were normal.

\section{BIBLIOGRAFIA}

1. CARMICHAEL, E. A.; DIX, M. R.; HALLPIK, C. S. - Organic affections of the eight nerve system. Brit. Med. Bull. 12:146-152 (maio) 1956. 2. SALTZMANN, M. - Clinical Audiology. Grune and Stratton, New York, 1949, pg. 39. 3. BARRE, J. A.; VINCENT, CL.; HELLE, Mlle. - Tumeur temporale gauche. Considerations sur les troubles cochlaires et vestibulaires avant l'intervention. Rev. Neurol. 1:376-384 (março) 1933. 4. SPIEGEL, E. A.; SOMMER, I. - Neurology of the Ear, Nose and Throat. Grune and Stratton, New York, 1944. 5. TERZIAN, H.; DALLE ORO, G. - Sindrome of Klüver and Bucy. Neurology 5:373 (junho) 1955. 6. GREINER, G. F.; KANTZER, L.; RHOMER, F. - Resultats des noveaux tests audiometriques après l'ablation du lobe temporal. Rev. d'Oto-Neuro-Oftalm., 23:249-256 (maio/junho) 1951. 7. SA, G. - Análise fonética da lingua portuguêsa falada no Brasil e a sua aplicação à logo-audiometria. Rev. Brasil de Medicina, 9:482-490 (julho) 1952. 8. PORTMANN, M.; PORTMANN, C. - Précis d'Audiometrie Clinique. Masson et Cie., Paris, 1954. 9. TUNTURI, A. R. - Audio-frequency localization in the acoustic cortex of the dog. Amer. J. Physiol., 141:387-403, 1944. 10. CAWTHORNE, T.; DIX, M. R.; HALlPIKE C. S.; HOOD, J. D. - The investigation of vestibular function. Brit. Med. Bull. 12:131-141 (maio) 1956.

Clínica Otorrinolaringológica - Hospital das Clínicas. Fac. Med. da Univ. de São Paulo - São Paulo, Brasil. 